\title{
Biomechanical Analysis of Implant Treatment for Fully Edentulous Maxillas*
}

\author{
Takaaki ARAHIRA**, Mitsugu TODO***, Yasuyuki MATSUSHITA**** \\ and Kiyoshi KOYANO**** \\ **Interdisciplinary Graduate School of Engineering and Science, Kyushu University, \\ 6-1 Kasuga-koen, Kasuga 816-8580, Japan \\ ${ }^{* * *}$ Research Institute for Applied Mechanics, Kyushu University, \\ 6-1 Kasuga-koen, Kasuga 816-8580, Japan \\ E-mail: todo@riam.kyushu-u.ac.jp \\ ${ }^{* * * *}$ Faculty of Dental Sciences, Kyushu University \\ 3-1-1 Maidashi, Higashi-ku, Fukuoka 812-0041, Japan
}

\begin{abstract}
Three-dimensional maxillary bone models of a male and a female patient were constructed using their CT-images. The distributions of Young's modulus were estimated from their bone mineral density distributions. Total six implants were embedded into each of the maxillary models. Finite element analysis of the maxilla models was then performed in order to assess the concentrations of strain energy density especially in the vicinities of the embedded implants. It was found that in both models, strain energy density was concentrated especially around the right-molar implant, suggesting outbreak of damage and subsequent absorption of bone tissue in this region. The female model with smaller size and lower bone density exhibited much higher localized concentration of strain energy density than the male model. Therefore, a modified placement of the right-molar implant was then introduced into the female model and such high concentration was effectively reduced by using the inclined and longer implant. It is thus concluded that this kind of three-dimensional modeling can clinically be used to predict the optimal implant treatment for each of dental patients.
\end{abstract}

Key words: Dental Biomechanics, CT-Image Based Modeling, Finite Element Analysis, Maxillary Bone Model, Bone Quality

\section{Introduction}

Occlusal function of patients with totally edentulous jaw bone can effectively be recovered by implant treatment, in which metal implants are directly screwed into the jaw bone and an artifical support is attached to the upper parts of the osseointegrated implants ${ }^{(1,2)}$. Although in recent years, the surgical technique and the biomaterials for the dental implants have dramatically been advanced, biomechanical problems such as fracture and loosening of the implants still exist in some actual crinical situations and must be solved in order to improve the safety and the durability of the implant treatment ${ }^{(3-5)}$.

In the implant treatment for a patient with totally edentulous jaw bone, in general, four to eight implants were inserted into both the maxilla and the mandible ${ }^{(6-8)}$, depending on the structural stability, bone density and the economical condition of the patient. Thus, firm occlusal forces during daily activities and sometimes unexpected forces by, for example, bruxism are supported by those embedded implants and the mechanical stresses were directly transmitted into the jaw bones. On the other hand, in a healthy jaw bone with

${ }^{*}$ Received 28 May, 2010 (No. 10-0228) [DOI: 10.1299/jbse.5.526]

Copyright $\odot 2010$ by JSME 
fourteen teeth for each, such stresses are transmitted into the bones through a soft tissue called periodontal ligament surrounding each tooth root and hence, the stresses are dramatically reduced by the viscoelastic damping effect of the ligament ${ }^{(9-11)}$. It is therefore easily expected that a jaw bone with artificial implants is facing much severer mechanical situations than a jaw bone with healthy teeth. This kind of excessive mechanical stimulus has been considered to cause bone absorption adjacent to the implants ${ }^{(12-14)}$, resulting in the loosening and the subsequent removing of the implants. Therefore, finite element analysis of jaw bones with implants has actively been conducted in order to understand such mechanical conditions in the vicinity of the implants ${ }^{(15-16)}$.

In the computational analyses of jaw bones, mandibles have mainly been investigated by constructing their three-dimensional models ${ }^{(17-21)}$ and few attempts have been made to study maxillas computationally. In general, structure and mechanical properties of maxillas are more complex than those of lower mandibles ${ }^{(22)}$, and it makes resulting in increase of the difficulty and the risk of the surgical treatments ${ }^{(23)}$. For example, hollow structures named maxillary sinus exist in the maxillas, and the bone tissue under the sinus is relatively thin that makes the placement of implants difficult. In the vicinity of the maxillary sinus, an implant is usually tried to be inserted into the rear or front part of the sinus, or inclined to avoid the sinus.

In the field of computational mechanics, CT-image based modeling has actively been developed to construct the realistic models of bone structures considering their three-dimensional shapes, and has effectively been applied to the clinical problems in orthopedics $^{(24-27)}$ and dentistry ${ }^{(28-34)}$. In this modeling procedure, detailed bone models are constructed from a series of CT-images by extracting the cross-sectional areas corresponding to the bones. The Hounsfield values of the CT-images can be used to estimate the bone mineral densities and subsequently, the distribution of Young's modulus are predicited from the distribution of the bone densities ${ }^{(35)}$. Furthermore, in the field of the computational biomechanics for bone tissue, the remodeling mechanism has been tried to be simulated by using a variety of theoretical approaches ${ }^{(36-49)}$. These approaches can roughly be devided into two categories, macroscopic and microscopic approaches. One of the well known macroscopic approaches is based upon a mechanical hypothesis in which the bone remodeling can be contorolled by strain energy density ${ }^{(40,41,44-48)}$. On the other hand, one of the well established microscopic approaches tries to understand the remodeling mechanism by using the biomechanical responses of bone related cells such as osteocytes ${ }^{(49)}$.

In this study, two different types of maxilla models varying in the shape and the bone quality were constructed using the CT images of the edentulous jaw bones of a female and a male patient. The distribution of Young's modulus was considered in the modeling by using the theoretical relationship between bone density and Young's modulus ${ }^{(24)}$. As a standard implant treatment, six implants were embedded into each of the maxilla models. Finite element analysis was then performed in order to characterize the effects of the implant treatment on the distribution of strain energy density in the maxillas. The effects of the different bone structure and quality were also assessed by comparing the two different models. A modification on the implant treatment was then successfully made to reduce the severe concentration of strain energy density observed in the female maxilla model.

\section{Finite Element Models and Analysis}

Two different types of maxilla models were constructed by using the CT images of the jaw bones of an 84 years old male and a 65 years old female. The total number of the images and the slice distance were 80 and $0.5 \mathrm{~mm}$ for the male and 37 and $1 \mathrm{~mm}$ for the female. Mechanical Finder (RCCM, Inc.), a software for finite element modeling and analysis of bone structure, was used in this study. Four-nodes tetrahedral elements were 
used to construct a finite element model of the maxilla and the total number of elements and nodes were 134223 and 630675 for the male model and 110052 and 505919 for the female model. The three-dimensional solid models and the finite element models are shown in Fig.1. The models shown in Fig.1 had the limited upper and side boundaries because only the limited regions of maxilla in which implants were supposed to be inserted were chosen by the dentist in charge and taken by $\mathrm{CT}$ in order to minimize the effects of X-ray radiation to the patients. It is also noted that the flatness of the lower part of the female model was caused by the unclearness of especially the boundary regions of the original CT images. This is thought to be mainly related to the low bone density of the female patient.

The bone density, $\rho$, corresponding to each element was estimated from the averaged CT value (Hounsfield units) using the following formula ${ }^{(35)}$ :

$$
\begin{array}{ll}
\rho\left(\mathrm{g} / \mathrm{cm}^{3}\right)=(\mathrm{CT} \text { value }+1.4246) \times 0.001 / 1.0580 & \text { for } \mathrm{CT} \text { value }>-1 \\
\rho\left(\mathrm{g} / \mathrm{cm}^{3}\right)=0.0 & \text { for } \mathrm{CT} \text { value } \leq-1
\end{array}
$$

The Young's modulus of the element was then calculated from the corresponding bone density by using the relationship proposed by Keyak, et al., shown in Table $1^{(25)}$.

For each maxilla model, a prosthesis model consisting of six implants and a curved support was developed as shown in Fig.2. The positive direction of the Y-axis corresponds to the direction towards the posterior side of the maxilla. The positions of the implant insertion were determined on the basis of the clinical opinion given by a dentist. The diameter of all implants was chosen to be $3.75 \mathrm{~mm}$. The curved shapes of the supports were determined so that they fitted to the curved shapes of the maxillas. The material of the implant and the support was assumed to be pure titanium with the Young's modulus of 106 GPa and the Poisson's ratio of 0.3 . These prosthesis models were attached to the maxilla
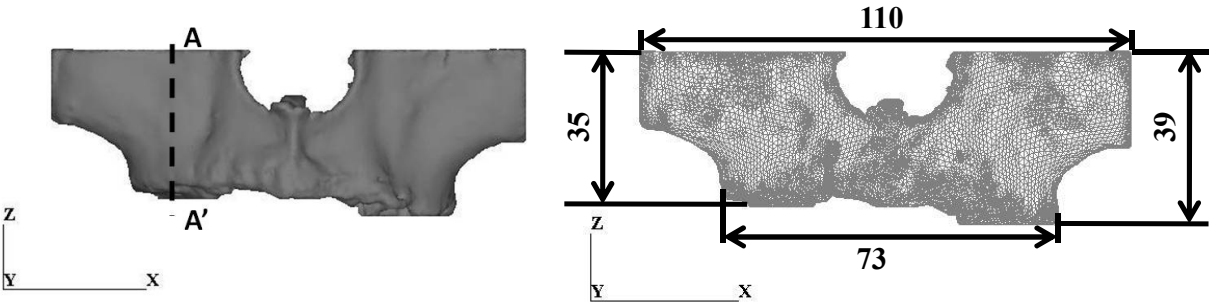

(a)84 years old male (unit:mm)
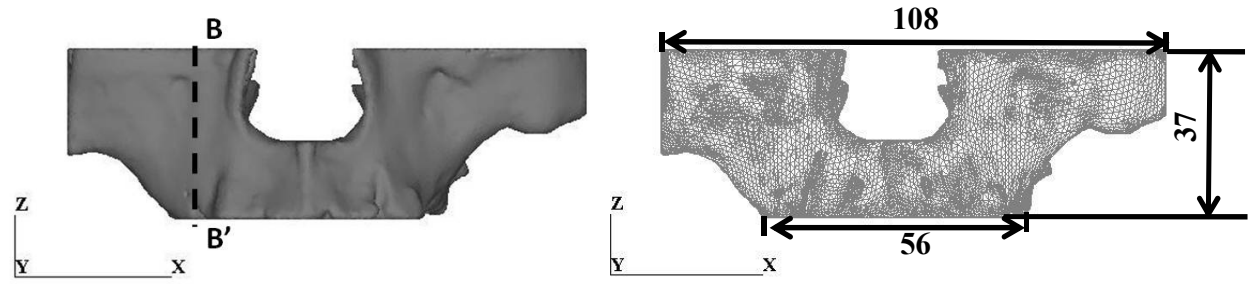

(b)65 years old female (unit:mm)

Figure 1 Computational models of edentulous maxillas. The left- and right-sides are the solid and finite element models, respectively.

Table 1 Relationship between bone density and Young's modulus ${ }^{(24)}$.

\begin{tabular}{c|c}
\hline Bone density $\left[\mathrm{g} / \mathrm{cm}^{3}\right]$ & Young's modulus [MPa] \\
\hline$\rho=0$ & $\mathrm{E}=0.001$ \\
\hline $0<\rho \leqq 0.27$ & $\mathrm{E}=33900 \rho^{2.20}$ \\
\hline $0.27<\rho \leqq 0.6$ & $\mathrm{E}=5307 \rho+469$ \\
\hline $0.6 \leqq \rho$ & $\mathrm{E}=10200 \rho^{2.01}$ \\
\hline
\end{tabular}



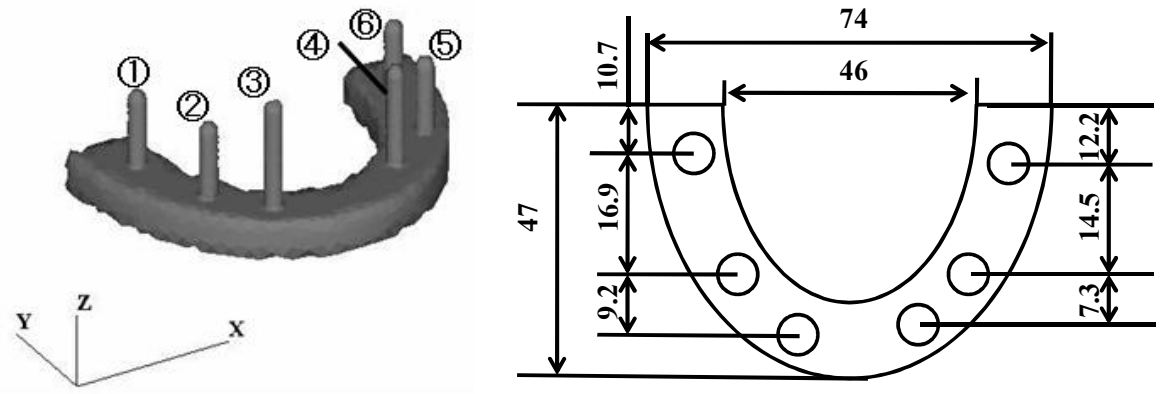

(a) 84 year old male (unit: $\mathrm{mm}$ )
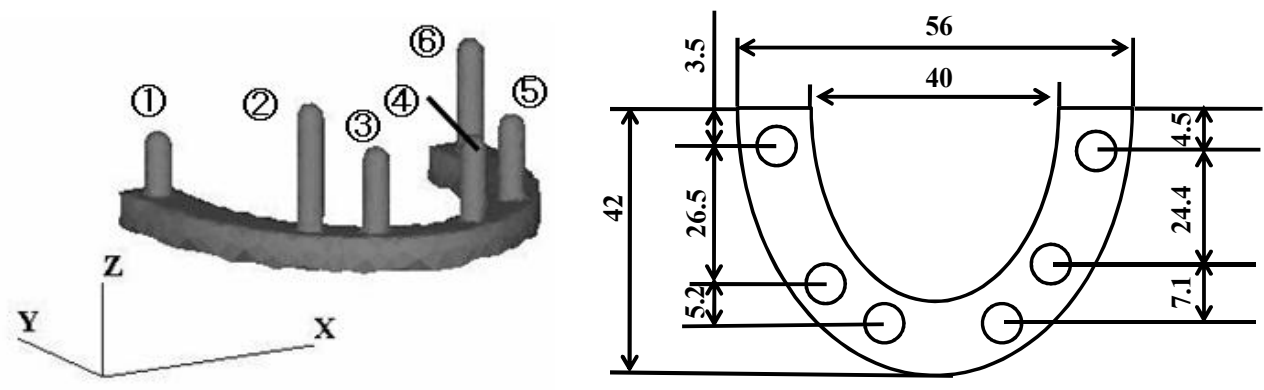

(b) 65 years old female (unit: $\mathrm{mm}$ )

Figure 2 Prosthesis models consisting of implants and curved support.

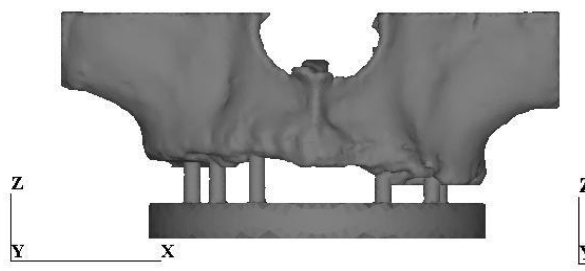

(a) 84 year old male

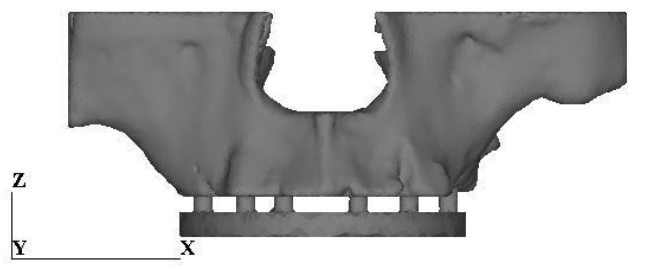

(b) 65 years old female

Figure 3 Maxilla models with prosthesis

Table 2 Length of each implant. The number in parenthesis is the insertion length.

\begin{tabular}{c|c|c|c|c|c|c|c}
\hline \multicolumn{2}{c|}{ Implant No } & 1 & $(2)$ & $(3$ & 4 & 6 & 6 \\
\hline \multirow{4}{*}{ Length[mm] } & Male & $\begin{array}{c}16 \\
(7.2)\end{array}$ & $\begin{array}{c}16 \\
(8.6)\end{array}$ & $\begin{array}{c}22 \\
(12.1)\end{array}$ & $\begin{array}{c}21 \\
(15.7)\end{array}$ & $\begin{array}{c}16 \\
(12.1)\end{array}$ & $\begin{array}{c}16 \\
(11.7)\end{array}$ \\
\cline { 2 - 8 } & \multirow{2}{*}{ Female } & 9 & 18 & 12 & 12 & 12 & 16 \\
& $(6)$ & $(14.9)$ & $(8.9)$ & $(9)$ & $(9)$ & $(11.9)$ \\
\hline
\end{tabular}

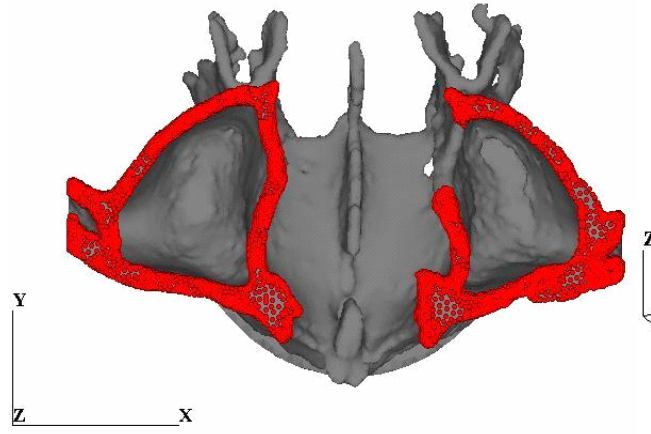

(a) Restraint condition

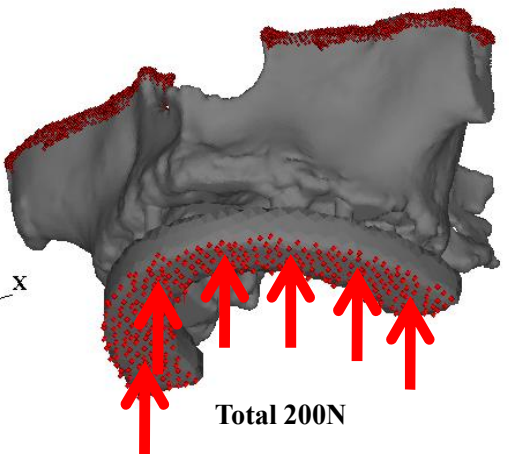

(b) Loading condition

Figure 4 Boundary conditions applied to maxillar model. 
models as shown in Fig.3. In a real edentulous maxilla, gingiva usually exists in the space between the maxillary and the curved support and neglected in this modeling. The boundaries between bone and implants were assumed to be perfectly bonded. The length of each implant was set to be maximized in each implantation position as shown in Table 2. In Table 2, the number in the parenthesis expresses the insertion length of the implant within bone tissue.

An actual dental occlusion can be done by the contact between maxilla and mandible subjected by muscle forces. It is therefore ideal to construct an entire jaw bone model to computationally simulate an occlusion condition. In this study, however, a simplified boundary condition was assumed to simulate an occlusion condition as a first step towards the dental biomechanical study for the implant treatment of edentulous maxilla. The boundary condition is shown in Fig.4. As a restraint condition, the top of the maxilla model was totally fixed as shown in Fig.4(a). An evenly distributed load of total $200 \mathrm{~N}$ was applied to the surface of the prosthesis in the + Z-direction as shown in Fig.4(b). It is noted that $200 \mathrm{~N}$ has been reported as an actual load subjected to jaw bones during an occlusion condition $^{(50)}$. The finite element analysis was then performed under those boundary conditions, and for each maxilla model, the distributions of strain energy density around the implants were examined in order to characterize the concentration condition of strain energy density.

\section{Results and Discussion}

\subsection{Distribution of Young's modulus}

The distributions of Young's modulus on the vertical cross-sectional areas at the right molar implant are shown in Fig.5. It is clearly seen that higher moduli were distributed in the cortical bone regions, indicating a typical bone structure. It is also noted that the male model exhibited higher modulus than the female model. The variations of the modulus along the dashed lines a-a' and b-b' are plotted in Fig.6. One modulus value was plotted at
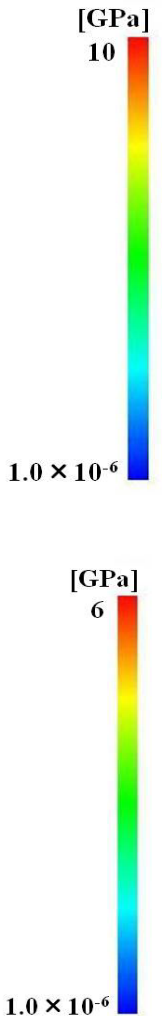
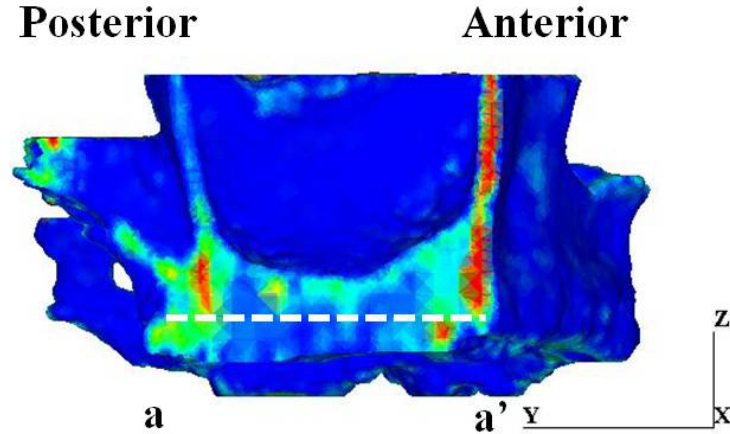

(a) 84 years old male

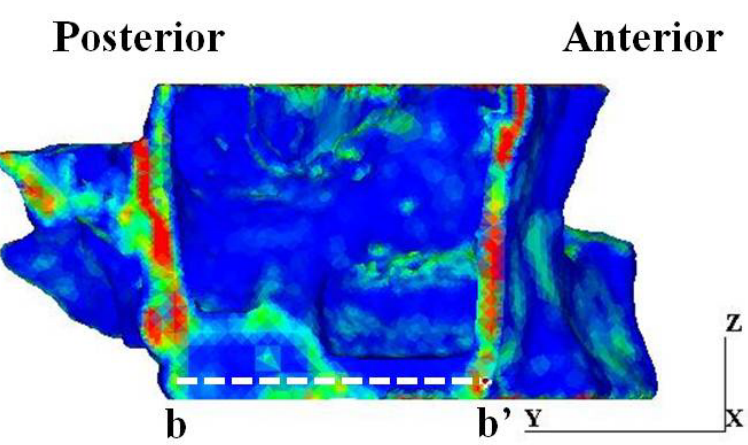

(b) 65 years old female 


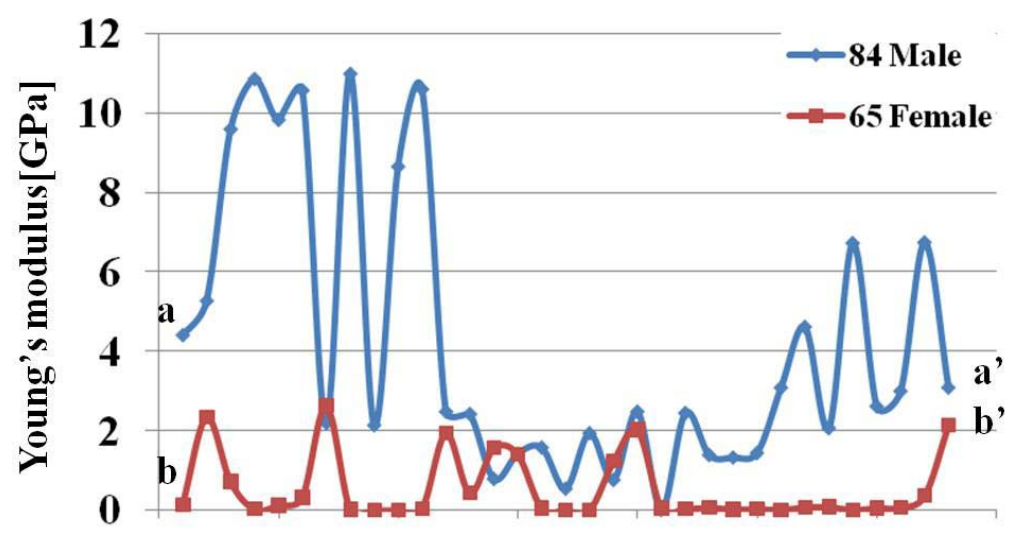

Figure 6 Distribution of Young's modulus along each dashed line in Figure 5.

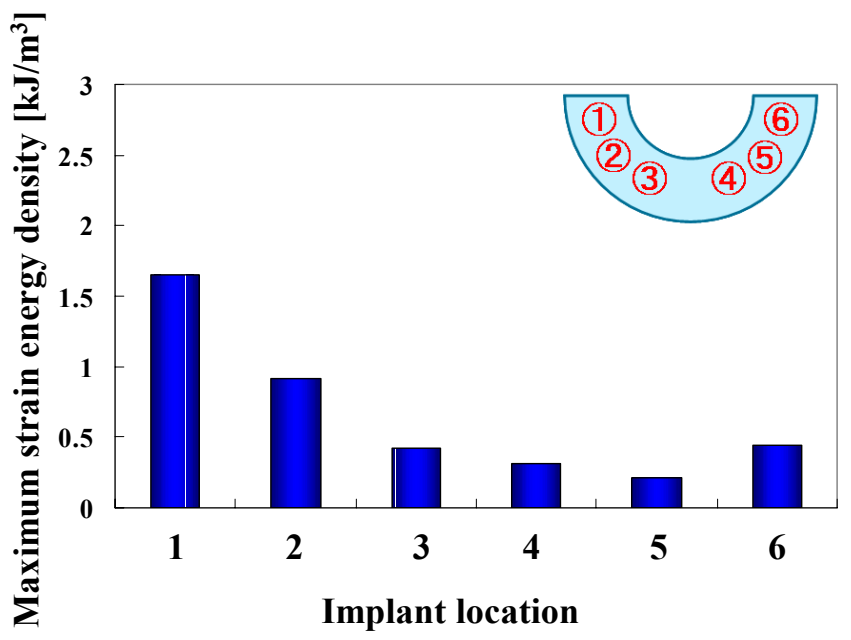

(a) 84 year old male

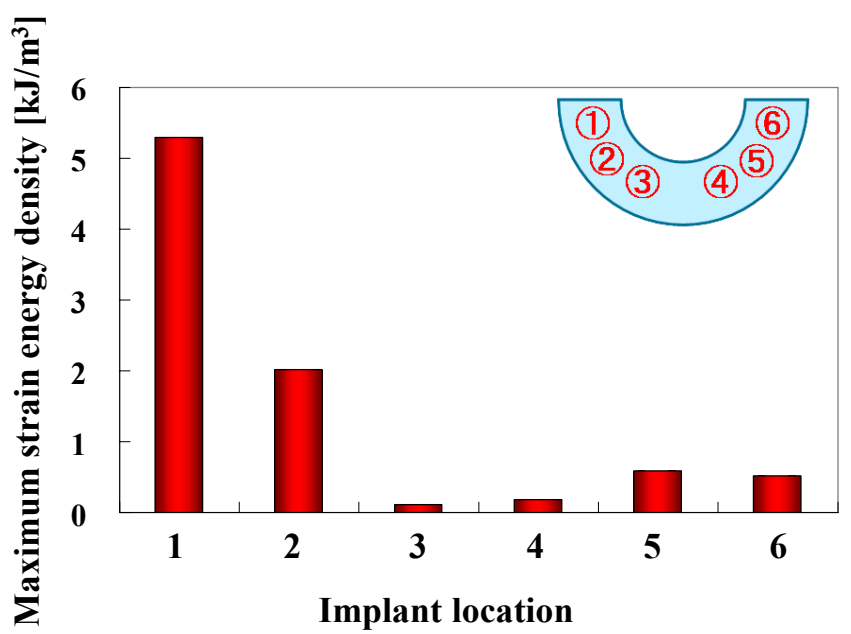

(b) 65 years old female.

Fig.7 Comparison of maximum strain energy density in the vicinity of implants. 
each element along the lines. It is clearly seen that for both the models, higher moduli were distributed in the cortical bone regions and the female model exhibited much lower distribution of the modulus than the male model. It should be noted that the modulus distribution in the male model was likely to be more accurate than that in the female model because the slice distance $(0.5 \mathrm{~mm})$ of the male CT images was just half of that of the female images and the unknown modulus values between the CT images were determined by averaging the known values. This is well known as the partial volume effects in the field of CT image analysis ${ }^{(51,52)}$.

\subsection{Maximum values and distributions of strain energy density}

The maximum values of strain energy density in bone in the vicinity of the six implants are shown in Fig.7. For both models, the highest maximum value existed in the vicinity of the far right-side molar implant (1). In the case of the female model, the length of the implant (1) was the shortest (see Table 2) and furthermore, the distance between the implants (1) and (2) was the longest (see Fig.2(b)), therefore the implants (1) was subjected by higher load and moment than the others. In the case of the male model, on the contrary, although the lengths of the right-side and the left-side molar implants (1) and (6) were the same, the insertion length of the implant (1) was the shortest as shown in Table 2 because of the shorter width of the right-side bone than the left-side as clearly seen in Fig.1(a). This shortest insertion length might cause the highest strain energy density.

The distribution patterns of strain energy density in the cross-sectional areas of the implants (1) are shown in Fig.8. It is clearly seen that strain energy density was mainly concentrated around the embedded implants. In the male model, the concentration was

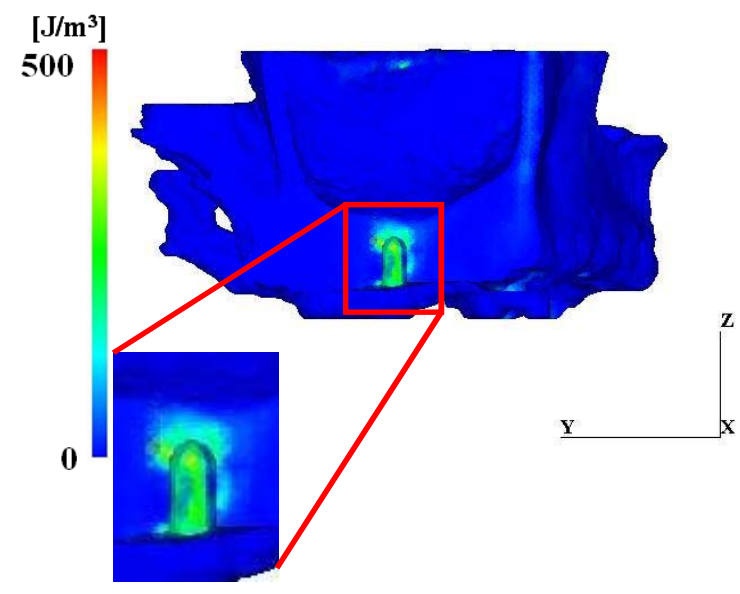

(a) 84 year old male

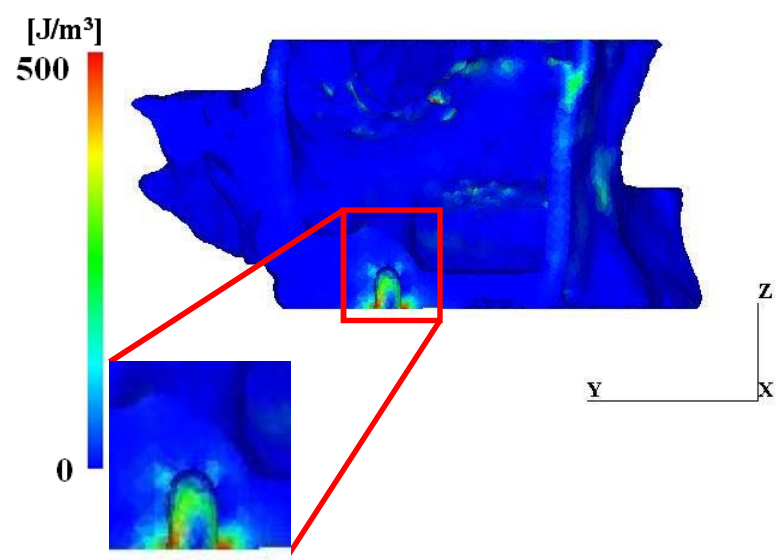

(b) 65 years old female

Figure 8 Distribution of strain energy density in the vicinity of the right molar implant. 
mostly located in the vicinity of the top of the implant, on the other hand, in the female model, strain energy density was concentrated in the region close to the bone surface, indicating that higher moment was applied to the implant (1).

It was thus found that the concentration of strain energy density around the implant (1) of the female model was much greater than that of the male model and actually the highest value in the female model was about 3.5 times larger than that in the male model. In the next section, a modified prosthesis model was introduced in order to reduce such high concentration of strain energy density.

\subsection{Modified prosthesis model for the female model}

In the female model, the far rihgt-side molar implant (1) exhibited extensively higher strain energy density than the male model. Considering the lower bone density and therefore weak bone structure of the femal model, such high concentration of strain energy density may cause damage and subsequent bone absorption around the implant (1). It is recommended to modify the implant (1) so that the concentration of strain energy density is resonably reduced. One of the effective approaches is thought to lengthen the implant (1), however, the sinus located above the implant prevents such lengthening. It is therefore, an inclied insertion technique was applied to the model. The modified prosthesis model introduced to the female model is shown in Fig.9. The length of the implant was changed from 9 to $15 \mathrm{~mm}$, and it was inclied by 45 degree to avoid the sinus.

The Maximum strain energy density around each implant is shown in Fig.10. It is clearly seen that the strain energy density around the implant (1) was dramatically reduced by the new insertion condition. The distribution patterns along the indicated lines around the implant (1) are shown in Fig.11. It is noted that the distribution pattern in the modified model was comparable to that in the male model.

It should be noted that such lengthened and inclined implant effectively improves the safety of the implant treatment; however, much higher surgical skill is required for the dentist. It is also noted that in an actual implant treatment, the number of the implants may unwillingly be reduced due to the structural weakness of the maxilla or the economical problem of the patient. Therefore, for each patient, risk assessment by the computational method is recommended in order to minimize the number of the implants and to optimize the positions and the lengths of the implants.

In actual medical treatments, threshold level of strain energy density could be very useful in order to perform the risk assessment for bone absorption using the computational analysis during the preoperative planning. Further study needs to be done to find such threshold level and establish the computer aided preoperative procedure.

\section{Conclusions}

Three-dimensional finite element models of totally edentulous maxillas of a male and female patient were developed using their CT-images. For each model, a prosthesis model including six-implants and a curved support was attached to the maxilla on the basis of the clinical consideration by a dentist. The distribution of Young's modulus was considered using the distribution of the bone mass density determined from the CT values. Finite element analysis was then performed to assess the effects of the implantation on the concentration of strain energy density that has been considered to be a macroscopic parameter controlling bone absorption around the implants. The conclusions are summarized as follows:

(1) In both the maxilla models, strain energy density was severely concentrated especially around the far right-molar implant (1), and the concentration in the female model was much higher than in the male model, suggesting bone absorption around the implant (1) of the female model. 


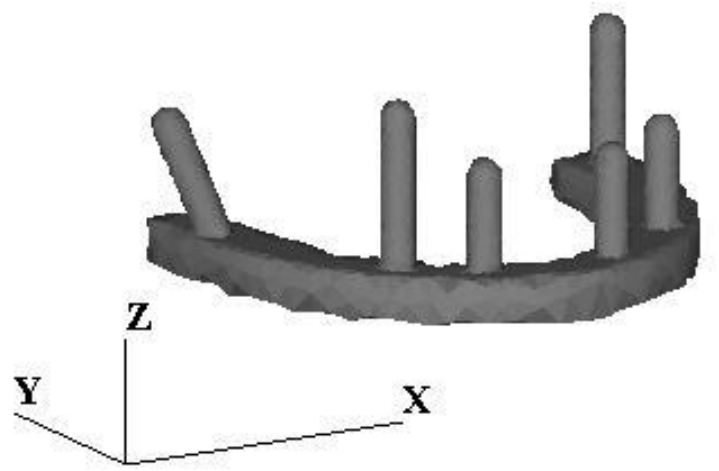

Figure 9 The modified prosthesis with implant model.

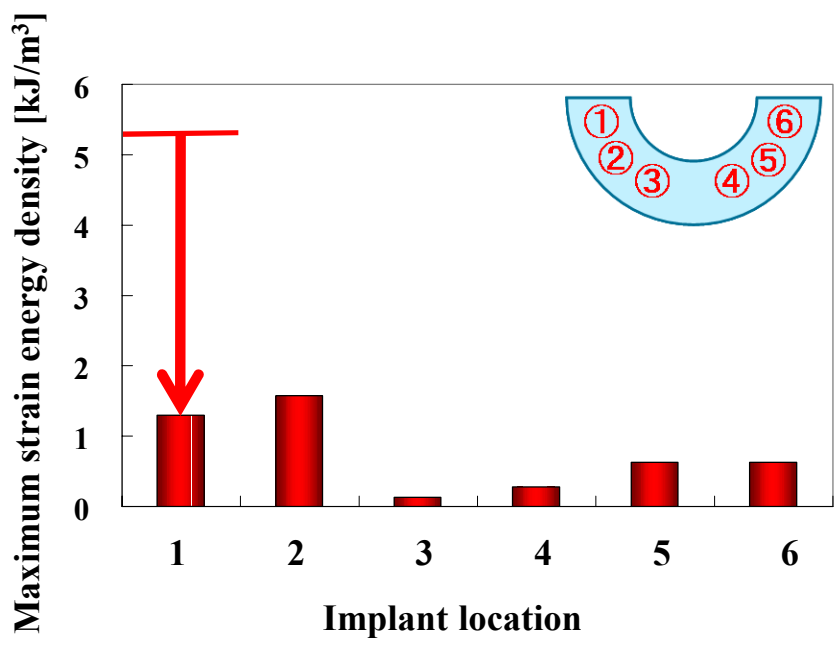

Figure 10 Maximum strain energy density in the vicinity of implants about modified model.
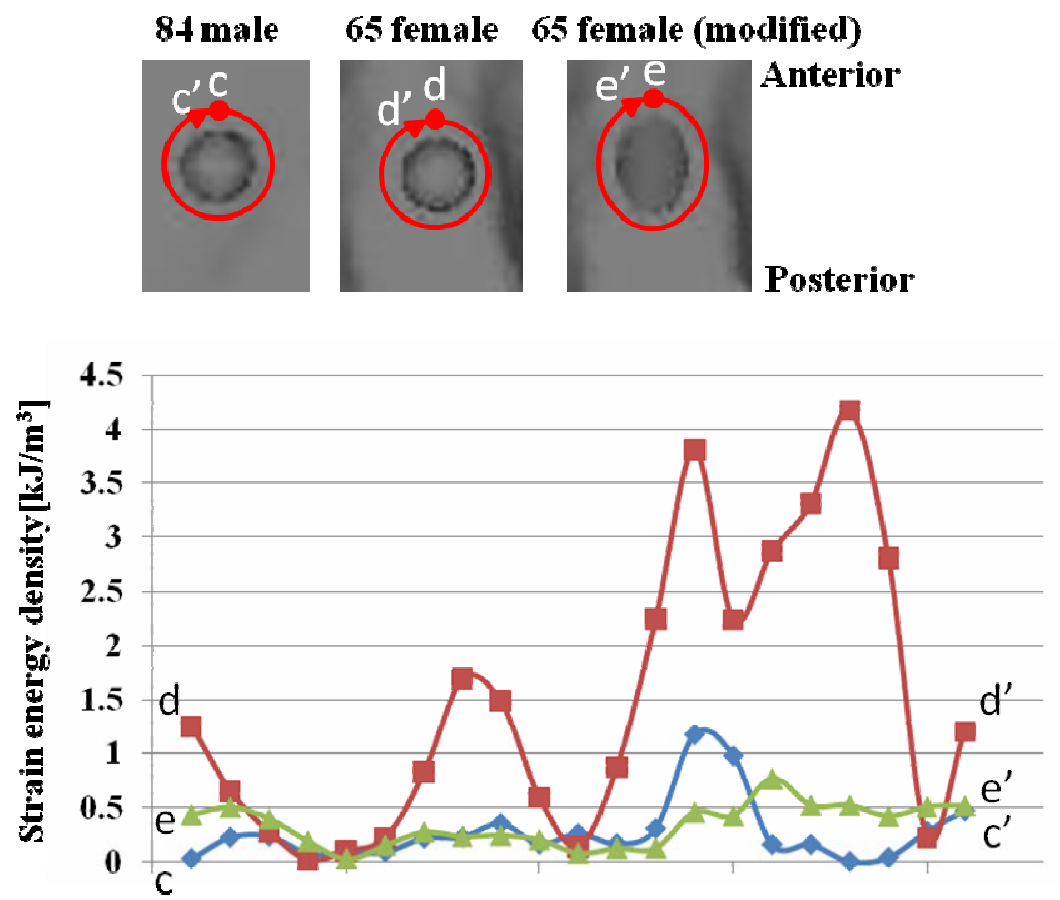

Figure 11 Distribution patterns of strain energy density along the lines around the implant (1). 
(2) The high concentration of strain energy density around the implant (1) was thought to be attributed to the shortest insertion length of the implant, resulting in the smallest contact area with bone tissue. For the female model, furthermore, the longer distance between the implants (1) and (2) was also considered to result in the higher moment subjected to the implant (1).

(3) The implant (1) of the female model was replaced by a longer and inclined implant. The concentration of strain energy denisty was then successfully reduced by this modification, although higher surgical skill may be required for this kind of implantation.

\section{References}

(1) Bellini, C.M., Romeo, D., Galbusera, F., Taschieri, S., Raimondi, M.T., Zampelis, A., and Francetti, L., Comparison of tilted versus nontilted implant-supported prosthetic designs for the restoration of the edentuous mandible: a biomechanical study. Journal of Oral \& Maxillofacial Implants, Vol.24(2009), pp. 511-517.

(2) Fueki, K., Kimoto, K., Ogawa., T., Garrett, N.R., Effect of implant-supported or retained dentures on masticatory performance: A systematic review, Journal of Prosthetic Dentistry, Vol.98(2007), pp.470-477.

(3) Richard P. Kinsel, Dongming Lin, Retrospective analysis of porcelain failures of metal ceramic crowns and fixed partial dentures supported by 729 implants in 152 patients: Patient-specific and implant-specific predictors of ceramic failure, The Journal of Prosthetic Dentistry, Vol.101 (2009), pp.388-394.

(4) Marianthi G. Manda, Pandora P. Psyllaki, Dimitrios N. Tsipas, Petros T. Koidis, Clinical Device-related article observations on an In-vivo failure of a titanium dental implant/abutment screw system: A case report, Journal of Biomedical Materials Research, Part B Applied Biomaterials, Vol.89 (2009), pp.264-273.

(5) Flemming Isidor, Influence of forces on peri-implant bone, Clinical Oral Implants, Vol.17 (2006), pp.8-18.

(6) Sadowsky, S.J., Treatment considerations for maxillary implant overdentures: A systematic review, Journal of Prosthetic Dentistry, Vol.97(2007), pp.340-348.

(7) Turkyilmaz, I., Company, A.M., McGlumphy, E.A., Should edentulous patients be constrained to removable complete dentures? the use of dental implants to improve the quality of life for edentulous patients, Gerodontology, Vol.27(2010), pp.3-10.

(8) Carlsson, G.E., Omar, R., The future of complete dentures in oral rehabilitation. A critical review, Journal of Oral Rehabilitation, Vol.37(2010), pp.143-156

(9) Dorow, C., Krstin, N., Sander, F.-G., Experiments to determine the material properties of the periodontal ligament, Journal of Orofacial Orthopedics, Vol.63(2002), pp.94-104.

(10) Komatsu, K., Shibata, T., Shimada, A., Analysis of contribution of collagen fibre component in viscoelastic behaviour of periodontal ligament using enzyme probe, Journal of Biomechanics, Vol.40(2007), pp.2700-2706.

(11) Qian, L., Todo, M., Morita, Y., Matsushita, Y., Koyano, K., Deformation analysis of the periodontium considering the viscoelasticity of the periodontal ligament, Dental Materials, Vol.25(2009), pp.1285-1292.

(12) Isidor, F., Loss of osseointegration caused by occlusal load of oral implants. A clinical and radiographic study in monkeys, Clinical oral implants research, Vol.7(1996), pp.143-152.

(13) Isidor, F., Histological evaluation of peri-implant bone at implants subjected to occlusal overload or plaque accumulation, Clinical oral implants research, Vol.8(1997), pp.1-9.

(14) Matarasso, S., Salvi, G.E., Iorio Siciliano, V., Cafiero, C., Blasi, A., Lang, N.P., Dimensional ridge alterations following immediate implant placement in molar extraction sites: A six-month prospective cohort study with surgical re-entry, Clinical Oral Implants Research, Vol.20(2009), pp.1092-1098. 
(15) Piscopo, G., Pezzuti, E., Valentini, P.P., Three-Dimensional Finite-Element Analysis of Immediate Loading Dental Implants, Journal of Biomechanical Science and Engineering, Vol.3(2008), pp.312-323.

(16) Tseng, C.-G., Jiang, Y.-S., Shih, K.-S., Mechanics Comparison of Various Designs of Implant-supported Mandibular Restoration, Journal of Biomechanical Science and Engineering, Vol.3(2008), pp.275-286.

(17) Rubo, J.H.,Souza, E.A., Finite element analysis of stress in bone adjacent to dental implants, The Journal of oral implantology, Vol.34(2008), pp.248-255.

(18) Maezawa, N., Shiota, M., Kasugai, S., Wakabayashi, N., Three-dimensional stress analysis of tooth/implant-retained long-span fixed denture, International Journal of Oral and Maxillofacial Implants, Vol.22(2007), pp.710-718.

(19) Bellini, C.M., Romeo, D., Galbusera, F., Taschieri, S., Raimondi, M.T., Zampelis, A., Francetti, L., Comparison of tilted versus nontilted implant-supported prosthetic designs for the restoration of the edentuous mandible: a biomechanical study, The International journal of oral \& maxillofacial implants, Vol.24(2009), pp.511-517.

(20) Zarone, F., Apicella, A., Nicolais, L., Aversa, R., Sorrentino, R., Mandibular flexure and stress build-up in mandibular full-arch fixed prostheses supported by osseointegrated implants, Clinical Oral Implants Research, Vol.14(2003), pp.103-114.

(21) Din, X., Zhu, X.,-H., Liao, S.,-H., Zhang, X.-H., Chen, H., Implant-bone interface stress distribution in immediately loaded implants of different diameters: a three-dimensional finite element analysis, Journal of Prosthodontics, Vol.18(2009), pp.393-402.

(22) Seong W. -J., Kim U. -K., Swift J. Q., Heo Y. -C., Hodges J. S., Ko C. -C., Elastic properties and apparent density of human edentulous maxilla and mandible, Journal of Oral and Maxillofacial Surgery, Vol.38 (2009), pp.1088-1093.

(23) Adell, R., Lekholm, U., Rockler, B., Branemark, P.I., A 15-yuar study of osseointegrated implants in the treatment of the edentulous jaw, International Journal of Oral Surgery, Vol.10(1981), pp.387-416.

(24) Keyak, J.H., Rossi, S.A., Jones, K.A., Skinner, H.B., Prediction of femoral fracture load using automated finite element modeling, Journal of Biomechanics, Vol.31 (1998), pp.125-133.

(25) Reina, J.M., Garcia-Aznar, J.M., Dominguez, J., Doblare, M., Numerical estimation of bone density and elastic constants distribution in a human mandible, Journal of Biomechanics, Vol.40 (2007), pp.828-836.

(26) Ong, K.L., Kurtz, S.M., Manley, M.T., Rushton, N., Mohammed, N.A., Field, R.E., Biomechanics of the Birmingham hip resurfacing arthroplasty, Journal of Bone and Joint Surgery - Series B, Vol.88 (2006), pp.1110-1115.

(27) Teoh, S.H., Chui, C.K., Bone material properties and fracture analysis: Needle insertion for spinal surgery, Journal of the Mechanical Behavior of Biomedical Materials, Vol.1(2008), pp.115-139.

(28) Yu H. S., Baik H. S., Sung S. J., Kim K. D., Cho Y. S., Three-dimensional finite-element analysis of maxillary protraction with and without rapid palatal expansion, European Journal of Orthodontics, Vol.29 (2007), pp.118-125.

(29) Akca, K., Iplikcioglu, H., Finite element stress analysis of the effect of short implant usage in place of cantilever extensions in mandibular posterior edentulism, Journal of Oral Rehabilitation, Vol.29 (2002), pp.350-356.

(30) Ziebowicz, A., Marciniak, J., The use of miniplates in mandibular fractures: biomechanical analysis, Journal of Materials Processing Technology, Vol.175 (2006), pp.452-456.

(31) Reimann, S., Keiling, L., Jager, A., Bourauel, C., Biomechanical finite-element investigation of the position of the centre of resistance of the upper incisors, European Journal of Orthodontics, Vol.29 (2007), pp.219-224.

(32) Daas, M., Dubois, G., Bonnet, A.S., Lipinski, P., Rignon-Bret, C., A complete finite 
element model of a mandibular implant-retained overdenture with two implants: Comparison between rigid and resilient attachment configurations, Medical Engineering Physics, Vol.30 (2008), pp.218-225.

(33) Boccaccio, A., Prendergast, P.J., Pappalettere, C., Kelly, D.J., Tissue differentiation and bone regeneration in an osteotomized mandible: a computational analysis of the latency period, Medical and Biological Engineering and Computing, Vol.46 (2008), pp.283-298.

(34) Arahira, T., Todo, M., Matsushita, Y., Koyano, K., Assessment of Mechanical Stability and Safety for Fully Edentulous Maxilla with Dental Implants, Journal of Solid Mechanics and Materials Engineering, (2010) (in press)

(35) Tawara, D., Sakamoto, J., Oda, J., Finite element analysis considering material inhomogeneousness of bone using "ADVENTURE system", JSME International Journal, Series C : Mechanical Systems, Machine Elements and Manufacturing, Vol.48(2005), pp.292-298.

(36) Lin, D., Li, Q., Li, W., Swain, M., Bone remodeling induced by dental implants of functionally graded materials, Journal of Biomedical Materials Research - Part B Applied Biomaterials, Vol.92(2010), pp.430-438.

(37) Jang, I.G., Kim, I.Y., Computational simulation of simultaneous cortical and trabecular bone change in human proximal femur during bone remodeling, Journal of Biomechanics, Vol.43(2010), pp.294-301.

(38) Lin, D, Li, Q., Li, W., Duckmanton, N., Swain, M., Mandibular bone remodeling induced by dental implant, Journal of Biomechanics, Vol.43(2010), pp.287-293.

(39) Mc Donnell, P., Harrson, N., Liebschner, M.A.K., Mc Hugh, P.E., Simulation of vertebral trabecular bone loss using voxel finite element analysis, Journal of Biomechanics, Vol.42(2009), pp.2789-2796.

(40) Chou, H.-Y., Jagodnik, J.J., Muftu, S., Predictions of bone remodeling around dental implant systems, Journal of Biomechanics, Vol.41(2008), pp.1365-1373.

(41) Weinans, H., Huiskes, R., Grootenboer, H.J., The behavior of adaptive bone-remodeling simulation models, Journal of Biomechanics, Vol.25(1992), pp.1425-1441.

(42) Hollister, S.J., Fyhrie, D.P., Jepsen, K.J., Goldstein, S.A., Application of homogenization theory to the study of trabecular bone mechanics, Journal of Biomechanics, Vol.24(1991), pp.825-839.

(43) Cowin, S.C., Van Buskirk, W.C., Surface bone remodelling induced by a medullary pin, Journal of Biomechanics, Vol.12(1979), pp.269-276.

(44) Eser, A., Tonuk, E., Akca, K., Cehreli, M.C., Predicting time-dependent remodeling of bone around immediately loaded dental implants with different designs, Medical Engineering and Physics, Vol.32(2010), pp.22-31.

(45) Bonnet, A.S., Postaire, M., Lipinski, P., Biomechanical study of mandible bone supporting a four-implant retained bridge. Finite element analysis of the influence of bone anisotropy and foodstuff position, Medical Engineering and Physics, Vol.31(2009), pp.806-815.

(46) Qian, L., Todo, M., Matsushita, Y., Koyano, K., Finite Element Analysis of Bone Resorption Around Dental Implant, Journal of Biomechanical Science and Engineering, Vol.4(2009), pp.365-376.

(47) Mellal, A., Wiskott, H.W.A., Botsis, J., Scherrer, S.S., Belser, U.C., Stimulating effect of implant loading on surrounding bone. Comparison of three numerical models and validation by in vivo data, Clinical Oral Implants Research, Vol.15(2004), pp.239-248.

(48) Huiskes, R., Weinans, H., Grootenboer, H.J., Dalstra, M., Fudala, B., Slooff, T.J., Adaptive bone-remodeling theory applied to prosthetic-design analysis, Journal of Biomechanics, Vol.20(1987), pp.1135-1150.

(49) Tsubota K., Suzuki, Y., Yamada T., Hojo M., Makinouchi A., Adachi T., Computer simulation of trabecular remodeling in human proximal femur using large-scale voxel FE models: Approach to understanding Wolff's law, Journal of Biomechanics, Vol.42(2009), 
pp.1088-1094.

(50) Mericske-Stern, R., Assal, P., Mericske, E., Bürgin, W., Occlusal force and oral tactile sensibility measured in partially edentulous patients with ITI implants, The international journal of oral \& maxillofacial implants, Vol.10(1995), pp.345-353.

(51) Helgason, B., Taddei, F., Pálsson, H., Schileo, E., Cristofolini, L., Viceconti, M., Brynjólfsson, S., A modified method for assigning material properties to FE models of bones, Medical Engineering \& Physics, Vol.30(2008), pp. 444-453.

(52) Chen, G., Schmutz, B., Epari, D., Rathnayaka, K., Ibrahim, S., Schuetz, M.A., Pearcy, M.J., A new approach for assigning bone material properties from CT images into finite element models, Journal of Biomechanics, Vol.43(2010), pp. 1011-1015. 